\title{
ANALISIS MINAT BELAJAR SISWA MENGGUNAKAN \\ MODEL PROBLEM BASED LEARNING DENGAN PENDEKATAN STEM PADA MATERI VEKTOR DI KELAS X MIPA 3 SMAN 2 JEMBER
}

\author{
Irma Septiani $^{1}$, Albertus Djoko Lesmono ${ }^{2}$, Arif Harimukti ${ }^{3}$ \\ ${ }^{1)}$ Program Studi Pendidikan Fisika FKIP Universitas Jember \\ ${ }^{2)}$ SMA Negeri 2 Jember \\ Email: irmasepti214@gmail.com
}

\begin{abstract}
This research to describe the learning interests of students of class $X$ MIPA 3 of SMAN 2 Jember on vector material using the Problem Based Learning model with STEM approach. The method used in this study is a survey using a questionnaire. Indicators of learning interest questionnaire include feelings of pleasure, attention, interest, and student participation. The questionnaire has 20 statements that represent indicators of student interest in learning. The questionnaire was distributed to students of SMAN 2 Jember in MIPA 3 class X, with a total of 36 students. The average percentage results obtained for each indicator are feeling happy $72.3 \%$ in the "medium" category, $77.5 \%$ in the "high" category, $75.2 \%$ interest in the "medium" category, and $53.1 \%$ student participation in the "low" category. These results indicate that the attention gets the highest percentage while the lowest participation.
\end{abstract}

Keywords: Vector, interest in learning, Problem Based Learning, STEM Approach

\section{PENDAHULUAN}

Belajar adalah perubahan tingkah laku yang dapat mengarah kearah positif dan negative atau bisa mengarah ke tingkah laku baik dan tingkah laku buruk (Purwanto, 2010: 85). Djamarah (2008: 13) mengatakan belajar adalah serangkaian kegiatan untuk memperoleh suatu perubahan tingkah laku yang merupakan hasil dari pengalaman individu dalam interaksi dengan lingkungannya menyangkut kognitif, afektif serta psikomotorik. Sedangkan Slameto (2010: 3) mengatakan belajar merupakan usaha individu untuk memperoleh perubahan tingkah laku sebagai hasil dari interaksi individu dengan lingkungannya.

Dari definisi beberapa ahli tersebut, maka dapat disimpulkan bahwa belajar merupakan suatu proses, suatu kegiatan, bukan suatu hasil atau tujuan. Belajar lebih luas dari itu, yakni siswa harus mengalami. Belajar merupakan suatu proses untuk mencapai suatu tujuan yaitu hasil belajar yang terlihat setelah pembelajaran berakhir. Perubahan tingkah laku merupakan hasil dari pembelajaran yang dilakukan.

Hasil belajar siswa dipengaruhi oleh dua faktor yaitu faktor internal dan faktor eksternal siswa. Faktor internal siswa diantaranya meliputi gangguan kesehatan, cacat tubuh, dan faktor psikologis (intelegensi, minat belajar, perhatian, bakat, motivasi, kematangan dan kesiapan peserta didik), dan faktor kelelahan. Sedangkan faktor eksternal yang 
mempengaruhi proses dan hasil belajar siswa meliputi faktor keluarga, sekolah dan masyarakat (Majid, 2008). Penelitian ini mengkaji salah satu faktor internal yang mempengaruhi hasil belajar yaitu minat belajar.

Purwanto (2010: 66) menyebutkan bahwa minat merupakan landasan penting yang dapat mendorong siswa untuk belajar secara suka rela. Djamarah (2008: 191) mengatakan minat adalah suatu rasa lebih suka dan rasa ketrikatan pada suatu hal, kegiatan, atau aktivitas tanpa ada dorongan orang lain. Minat adalah penerimaan akan sesuatu hubungan antara diri sendiri dengan sesuatu di luar diri (Slameto, 2010: 182). Sementara itu, Wardiana (2005: 172) mengatakan minat adalah dorongan seseorang untuk melakukan suatu pekerjaan atau kegiatan.

Berdasarkan pendapat tersebut, maka pengertian minat sebagaimana tersebut dapat disimpulkan bahwa minat adalah perasaan yang mendorong seseorang untuk melakukan suatu kegiatan atau dorongan yang melatar belakangi seseorang melakukan sesuatu. Oleh karena itu disimpulkan bahwa minat belajar adalah dorongan yang dimiliki seseorang untuk melakukan kegiatan belajar.

Ada beberapa indikator siswa yang memiliki minat belajar yang tinggi, hal ini dapat dikenali melalui proses belajar di kelas maupun di rumah. Slameto (2010:180) menyatakan bahwa: "Minat adalah suatu rasa lebih suka dan rasa ketertarikan pada suatu hal atau aktivitas, tanpa ada yang menyuruh. Minat pada dasarnya adalah penerimaan akan suatu hubungan antara diri sendiri dengan sesuatu di luar diri. Semakin kuat atau dekat hubungan tersebut semakin besar minat. Suatu minat dapat diekspresikan melalui suatu pernyataan yang menunjukkan bahwa siswa lebih menyukai suatu hal daripada hal lainnya, dapat pula dimanifestasikan melalui partisipasi dalam suatu aktivitas. Siswa yang memiliki minat terhadap subjek tertentu cenderung untuk memberikan perhatian yang lebih besar terhadap subjek tertentu". Berdasarkan definisi tersebut, maka dapat disimpulkan indikator minat belajar yaitu rasa suka/senang dalam aktivitas belajar, rasa ketertarikan untuk belajar, adanya kesadaran untuk belajar tanpa disuruh, berpartisipasi dalam aktivitas belajar, memberikan perhatian yang besar dalam belajar.

Indikator minat ada empat, yaitu perasaan senang, ketertarikan siswa, perhatian siswa, dan keterlibatan siswa/partisipasi siswa (Safari, 2003: 60). Perasaan senang ditandai dengan siswa tersebut akan terus mempelajari ilmu yang disenanginya (tidak terpaksa). Dalam penelitian ini yaitu dilihat respon siswa terhadap materi yang diajarkan dan cara guru mengajarkannya. Ketertarikan siswa berhubungan dengan daya gerak yang mendorong untuk cenderung merasa tertarik pada orang, benda, kegiatan atau bisa berupa pengalaman afektif yang dirangsang oleh kegiatan itu sendiri. Dalam penelitian ini dilihat respon siswa meliputi rasa ingin tahu dan penerimaan akan tugas yang diberikan. Perhatian siswa merupakan konsentrasi atau aktivitas jiwa terhadap pengamatan dan pengertian, dengan mengesampingkan yang lain dari pada itu. Dalam hal ini dilihat bagaimana perhatian siswa saat mengikuti pembelajaran dan saat berdiskusi. 
Keterlibatan/ partisipasi siswa akan suatu objek yang mengakibatkan siswa tersebut senang dan tertarik untuk melakukan atau mengerjakan kegiatan dari objek tersebut. Pada poin ini diketahui apakah siswa tersebut sadar akan pentingnya belajar di luar sekolah.

Fisika merupakan ilmu yang mempelajari tentang gejala alam pada kehidupan sehari-hari sampai pada gejala alam yang sifatnya abstrak, sehingga siswa berpikir secara imajinatif (Sutarto dan Indrawati, 2010:1).

Vector sangat penting dan banyak contoh aplikasi vector di berbagai cabang fisika. Vektor adalah objek geometris yang memiliki besar dan arah (sering kali divisualisasikan sebagai panah). Contoh dari penerapan vector antara lain : momentum, gaya, perpindahan, kecepatan, dan sebagainya (Bollen, L., dkk, 2017).

Pembelajaran merupakan suatu interaksi yang dilakukan siswa dan guru yang mana saat proses pembelajaran, guru mengarahkan peserta didik dalam kegiatan belajar agar suatu tujuan pembelajaran terlaksana dengan baik (Komera,2014:29). Dalam pembelajaran fisika siswa dituntut untuk membangun pengetahuannya sendiri berdasarkan peran aktifnya pada proses pembelajaran (Zahro, et al., 2017:64). Adapun kendala yang sering ditemui yaitu penggunaan model, metode, dan pendekatan pembelajaran yang kurang tepat, kurang cocoknya penggunaan media pembelajaran dan kurang perhatian pada minat siswa (Purwanto, 2010).

Berdasarkan permasalahan tersebut, maka untuk meningkatkan daya saing di era modern ini salah satunya dengan memberlakukan pembelajaran STEM (Science, Technology, Engineering, and Mathematics). Deslauriers dkk., (dalam Roberts, 2012:2) menyatakan bahwa "Students become enthuasiasthic when problem-based instruction is incorporated". Selain itu, Roberts (2012:2) mengungkapkan bahwa "STEM is appealing. Students enjoy classroom discussion and participation to solve a meaningful problem". Berdasarkan pernyataan tersebut, pendekatan STEM cocok di aplikasikan dengan model Problem Based Learning.

Tujuan pendidikan STEM adalah untuk meningkatkan pemahaman siswa tentang materi pembelajaran dengan menerapkan Science, Technology, Engineering, dan mathematics, selain itu yang paling penting adalah agar siswa mampu menerapkan pengetahuan tersebut untuk memecahkan masalah-masalah yang kompleks dengan mengembangkan kemampuan berpikir tingkat tinggi; menyiapkan kebutuhan sumber daya manusia abad 21; serta mengembangkan kompetensi di bidang STEM (Bybee, 2013). Pembelajaran dengan pendekatan STEM memiliki kecenderungan untuk meningkatkan kualitas pembelajaran dan meningkatkan motivasi dan minat siswa (Gallant, 2010).

Seperti yang telah disebutkan sebelumnya, pembelajaran sains yang sesuai dengan pendekatan STEM dapat dilakukan dengan model pembelajaran PBL (Problem Based Learning). Pembelajan dengan pendekatan STEM dapat dilakukan menggunakan beberapa model yang cocok dan hasil penelitian menyebutkan bahwa STEM dapat meningkatkan literasi sains 
siswa, minat, motivasi, dan sebagainya.

Savery, (2006) menyatakan bahwa problem-based learning adalah suatu model pembelajaran dengan mengutamakan pendekatan student centered yang mendorong siswa untuk melakukan kegiatan penelitian, memadukan antara teori dan praktek, mengaplikasikan pengetahuan dan keterampilan siswa untuk memecahkan masalah nyata. Problem-based learning merupakan model pembelajaran yang berfokus pada siswa dengan mengarahkan siswa untuk belajar mandiri dan terlibat langsung secara aktif dalam pembelajaran berkelompok.

Karakteristik model pembelajaran PBL menurut Herman (2012) sebagai berikut. a) pembelajaran berpusat pada siswa; b) aktif dalam kegiatan diskusi dalam kelompok kecil; c) diskusi dipicu oleh masalah yang bersifat integrasi interdisiplin yang didasarkan pada pengalaman/ kehidupan nyata; d) diskusi secara aktif merangsang siswa untuk menggunakan prior knowledge; e) siswa terlatih belajar mandiri yang dapat menjadi dasar bagi pembelajaran seumur hidup; f) pembelajaran berjalan efektif karena informasi yang dikumpulkan secara mandiri sesuai dengan yang dibutuhkan (need to know basis).

Berdasarkan karakteristik yang telah disebutkan, fokus pembelajaran dengan menggunakan model PBL adalah terletak pada pemecahan masalah. Permasalahan yang akan dipecahkan bersifat autentik. Hal ini sesuai dengan pendapat Graft dan Kolmos (2003) yang mengemukakan bahwa "PBL merupakan metode pembelajaran yang memulai belajar siswa dengan menciptakan kebutuhan untuk memecahkan masalah autentik". Masalah autentik digunakan sebagai stimulus dalam pembelajaran. Permasalahan tersebut merupakan modal utama yang dapat mendorong siswa mengumpulkan informasi dalam memecahkan masalah. Sehingga pembelajaran akan lebih bermakna dengan siswa memecahkan permasalahan yang bersifat autentik dengan mengaitkan materi pembelajaran dengan permasalahan sehari-hari.

\section{METODE PENELITIAN}

Metode yang digunakan dalam penelitian ini adalah survey. Metode survey dianggap tepat karena penelitian ini dilakukan untuk mengumpulkan informasi faktual melalui penggunaan angket. Sampel penelitian adalah 36 siswa Kelas $\mathrm{X}$ MIPA 3 di SMAN 2 Jember. Instrumen pengumpulan data berupa angket minat belajar siswa. Angket untuk mengukur persepsi responden mengenai minat belajar yang diukur melalui indikator perasaan senang, perhatian, ketertarikan, dan partisipasi siswa. Kuesioner tersebut berjumlah 20 item. Statistik deskriptif menggunakan skor yang digunakan untuk memperoleh gambaran tingkat persepsi responden mengenai minat belajar. Minat belajar siswa (tiap individu) dikategorikan dalam klasifikasi minat tinggi, minat sedang dan minat rendah. Untuk mendapatkan klasifikasi minat belajar siswa digunakan rumus:

Rentang Minat $=\frac{\text { Skor Maksimal-Skor Minimal }}{K}(1)$ 
Keterangan: Skor Maksimal $=80$, Skor Minimal $=20, \mathrm{~K}$ (Jumlah rentang kategori minat) $=3$. Jadi rentang minat:

$\frac{80-20}{3}=20$

Sehingga didapat rentang minat dari 3 kategori minat tersebut, yaitu: minat tinggi (nilai 60-80), minat sedang (nilai 40-59) dan minat rendah (nilai 20-39).

Untuk mengukur tingkat keberhasilan dari indikator minat digunakan rumus:

$$
\% A m=\frac{\sum A s}{N} \times 100 \%
$$

Keterangan $: \% A m=$ Persentase siswa berminat tinggi/ sedang/ rendah, $\sum$ As = Banyak siswa yang berminat tinggi/ sedang/ rendah, $\mathrm{N}=$ Banyak siswa yang hadir

Kemudian, untuk mengukur persentase per indicator menggunakan rumus:

$$
\% \text { In }=\frac{\sum I x}{\sum N} \times 100 \%
$$

Keterangan: $\%$ In $=$ Persentase indicator $1 / 2 / 3 / 4, \sum \mathrm{Ix}=$ jumlah skor indicator $1 / 2 / 3 / 4, \sum N=$ jumlah skor max indicator $1 / 2 / 3 / 4 \mathrm{x}$ jumlah siswa Adapun kriteria presentase minat belajar siswa menurut Arikunto ditunjukkan pada Tabel 1 berikut:

Tabel 1. Kriteria presentase minat belajar siswa

\begin{tabular}{cc}
\hline $\begin{array}{c}\text { Presentase skor } \\
\text { minat (\%) }\end{array}$ & Kriteria \\
\hline $76-100$ & Tinggi \\
\hline $56-75,9$ & Sedang \\
\hline $0-55,9$ & Rendah \\
\hline \multicolumn{2}{c}{ Sumber: Arikunto (2010) }
\end{tabular}

\section{HASIL DAN PEMBAHASAN}

Data tentang minat belajar pada materi vector menggunakan model Problem Based Learning dengan pendekatan STEM diperoleh dengan menggunakan angket. Minat belajar dalam penelitian ini diukur melalui empat indikator yaitu perasaan senang, perhatian, ketertarikan, dan partisipasi siswa.

Metode angket digunakan dengan cara memberikan sejumlah pernyataan terkait 4 indikator minat belajar. Angket berjumlah 20 pernyataan dengan 4 alternatif jawaban, yaitu selalu (SL), sering (SR), kadangkadang (KD), dan tidak pernah (TP). Pernyataan berbentuk pernyataan positif dan pernyataan negatif. Pernyataan nomor 1-6 mewakili indikator perasaan senang, pernyataan nomor 7-12 mewakili indikator perhatian, pernyataan nomor 13-16 mewakili indikator ketertarikan, pernyataan nomor 17-20 mewakili indikator partisipasi.

Berdasarkan hasil penelitian yang telah dilakukan, hasil menunjukkan bahwa 17 siswa dengan kategori minat tinggi, 15 siswa dengan kategori sedang, dan 4 siswa dengan kategori rendah. Dengan demikian, maka tingkat keberhasilan dari indicator minat belajar siswa adalah 47,2 \% siswa memiliki minat yang tinggi, $41,7 \%$ siswa memiliki minat belajar yang sedang, dan $11,1 \%$ siswa memiliki minat belajar yang rendah. Tabel 2 menyajikan tingkat keberhasilan dari indicator minat belajar siswa adalah sebagai berikut 
Tabel 2. Tingkat keberhasilan minat belajar

\begin{tabular}{|c|c|c|}
\hline Nilai & $\begin{array}{c}\text { Jumlah } \\
\text { siswa }\end{array}$ & Persentase \\
\hline $20-39$ & 4 & $11,1 \%$ \\
\hline $40-59$ & 15 & $41,7 \%$ \\
\hline $60-80$ & 17 & $47,2 \%$ \\
\hline
\end{tabular}

rata-rata yang diperoleh untuk setiap indicator yaitu perasaan senang $72,3 \%$ kategori "sedang", perhatian $77,5 \%$ kategori "tinggi", ketertarikan 75,2\% kategori "sedang", dan partisipasi siswa 53,1\% kategori "rendah". Hasil tersebut menunjukkan bahwa perhatian mendapat persentase paling tinggi sedangkan partisipasi yang paling rendah. Tabel 3 menyajikan skor klasifikasi minat belajar siswa.

Tabel 3. Klasifikasi minat belajar siswa

\begin{tabular}{llll}
\hline Indikator & Item & $\begin{array}{l}\text { Persent } \\
\text { ase }\end{array}$ & $\begin{array}{l}\text { Penafsir } \\
\text { an }\end{array}$ \\
\hline $\begin{array}{l}\text { Perasaan } \\
\text { senang }\end{array}$ & $1-6$ & $72,3 \%$ & Sedang \\
\hline Perhatian & $7-12$ & $77,5 \%$ & Tinggi \\
\hline $\begin{array}{l}\text { Ketertarika } 13-16 \\
\mathrm{n}\end{array}$ & $75,2 \%$ & Sedang \\
\hline Partisipasi & $17-20$ & $53,1 \%$ & Rendah \\
\hline \multicolumn{2}{c}{ Rata-rata } & $\mathbf{6 9 , 5 \%}$ & Sedang \\
\hline
\end{tabular}

Dari Tabel 3, maka dapat disimpulkan bahwa rata-rata minat belajar pada materi vector menggunakan model Problem Based Learning dengan pendekatan STEM ada pada kategori "sedang".

\section{SIMPULAN DAN SARAN}

Minat belajar siswa setelah diterapkan model pembelajaran Problem Based Learning dengan pendekatan STEM berada pada kategori "sedang". Hal ini berarti model pembelajaran Problem Based
Learning dengan pendekatan STEM dapat dijadikan alternative untuk meningkatkan minat belajar siswa pada pembelajaran Fisika.

Hasil penelitian menunjukkan bahwa salah satu indikator pada variabel minat belajar yaitu partisipasi dalam belajar mendapat skor terendah dibandingkan dengan indikator variabel minat belajar lainnya. Oleh karena itu perlu untuk memberikan motivasi lebih agar siswa lebih semangat dalam belajar di luar sekolah. Selain itu, dengan guru memberikan motivasi pentingnya belajar di luar sekolah tujuannya agar siswa memiliki hasrat yang lebih tinggi untuk belajar sehingga ketertarikan dalam belajar pada materi vector atau materi fisika lainnya akan semakin lebih baik.

\section{DAFTAR PUSTAKA}

Arikunto, Suharsimi. 2010. Prosedur Penelitian Suatu Pendekatan Praktik. Jakarta: Rineka Cipta

Bollen, L., Kampen, P. Van, Baily, C., Kelly, M., \& Cock, M. De. 2017. Student difficulties regarding symbolic and graphical representations of vector fields. Physical Review Physics Education Research, 13 (1), 1-17.

Bybee, R. W. 2013. The Case for STEM Education: Challenges and Opportunities. Arlington, Virginia: NSTApress.

Djamarah, S. B. 2008. Psikologi Belajar. Jakarta: Rineka Cipta. 
Gallant, D. J. 2010. Science, technology, engineering, and mathematics (STEM) education: McGraw-Hill Education. Retrieved from https://www. mheonline.

com/glencoemath/pdf/stem_educ ation.p df.

Graft, E. D. \& Kolmos A. 2003. Characteristics of Problem Based Learning. Journal Eng Ed. 19 (5). 657-662.

Herman, Rahmatina B. 2012. Filosofi PBL dan Strategi Pembelajaran. Medical Education Unit (MEU) Universitas Andalas

Komera, E. 2014. Belajar dan Pembelajaran Interaktif. Bandung: Refika Aditama.

Majid, A. 2008. Perencanaan Pembelajaran. Bandung: Remaja Rosdakarya.

Purwanto, N. 2010. Psikologi Pendidikan. Bandung: Remaja Rosdakarya.

Roberts, Amanda \& Diana Catu. 2012. Applying Instructional Strategies to Design and Tecnology Curriculum. Journal of STEM Education, 111-118.

Safari. 2003. Indikator Minat Belajar. Jakarta: Rineka Cipta.
Savery, J.R. 2006. Overview of Problem Based Learning: Definitions and Distinctions Interdisiplinary Journal of Problem Based Learning 1 (1) (Online) http: dx.doi.org/10.77716015-002

Slameto. 2010. Belajar dan Faktorfaktor yang Mempengaruhinya. Jakarta: Rineka Cipta.

Sutarto dan Indrawati. 2010. Diktat Media Pembelajaran Fisika. Jember: Universitas Jember.

Wardiana, U. 2005. Psikologi Umum. Jakarta: Bina Ilmu.

Zahro., L.U., V. Serevina., dan I. M Astra. 2017. Pengembangan Lembar Kerja Siswa (LKS) Fisika Dengan Menggunakan Strategi Relating, Experiencing, Applying, Cooperating, Transferring (React) Berbasis Karakter Pada Pokok Bahasan Hukum Newton. Jurnal Wahana Pendidikan Indonesia. 2(1): 6368 